\title{
O esporte náutico e a dinâmica da hélice tríplice no projeto Grael: um estudo de caso
}

\author{
Daniel Corrêa de Mattos* \\ Carlos Alberto Figueiredo da Silva** \\ José Pedro Sarmento Rebocho Lopes*** \\ José Maurício Capinussú****
}

\begin{abstract}
Resumo: Alguns projetos desenvolvidos no âmbito do esporte têm se destacado por apresentarem modelos inovadores. Este estudo focaliza o Projeto Grael e suas relações com o governo, com a indústria e com a universidade. Tem como objetivo geral promover a reflexão sobre o papel do esporte no desenvolvimento de regiões. O modelo teórico da hélice tríplice é utilizado para analisar a participação de diferentes atores. A conclusão aponta que o principal parceiro do projeto é a prefeitura da cidade de Niterói. A atuação das indústrias, basicamente, situa-se no âmbito do patrocínio. A universidade participa de forma tímida.
\end{abstract}

Palavras-chave: Educação Física. Projetos de investimento social. Esportes.

\section{INTRODUÇÃO}

Em 2003, a Assembléia Geral da Organização das Nações Unidas (ONU) proclamou 2005 como o Ano Internacional do Esporte e da Educação Física com o objetivo de incentivar investimentos dos governos na implementação das atividades físicas e esportivas. Ao fomentar o desenvolvimento do esporte, a ONU busca promover melhorias na educação, saúde, desenvolvimento e nos processos de paz.

\footnotetext{
*Mestre em Ciências da Atividade Física. Universidade Salgado de Oliveira, Niterói, RJ, Brasil. E-mail:pgcaf@nt.universo.edu.br

**Doutor em Educação Física. Professor do Programa de Mestrado em Ciências da Atividade Física da Universidade Salgado de Oliveira e Docente do Centro Universitário Augusto Motta. Niterói, RJ, Brasil. E-mail:ca.figueiredo@yahoo.com.br.

***Doutor em Ciências do Desporto. Diretor do Curso de Mestrado em Gestão Desportiva na Faculdade de Desporto. Universidade do Porto, Porto, Portugal. E-mail: psarmento@fade.up.pt ****Doutor em Comunicação e Cultura. Professor do Programa de Mestrado em Ciências da Atividade Física da Universidade Salgado de Oliveira. Niterói, RJ, Brasil. E-mail: pgcaf@nt.universo.edu.br
} 
Nesse contexto, alguns projetos desenvolvidos no âmbito do esporte têm se destacado por apresentarem modelos inovadores. No Brasil, o Projeto "Nomes", idealizado em 1996, na cidade de Niterói, no estado Rio de Janeiro, pautou-se pela ideia de aproveitar os nomes famosos da cidade, como estratégia para atrair crianças da rede pública municipal de ensino. Inicialmente surgiu o Projeto Grael voltado ao iatismo. Em seguida vieram: o Projeto Keller, triatlo, o Projeto Gerson, futebol, o Projeto Gugu, ginástica para a terceira idade e o Projeto Tatuí, surfe.

Diferentes atores participam na construção, fomento e crescimento desses projetos sociais esportivos. Este estudo pretende focalizar três atores principais: a universidade, o governo e a indústria, no sentido de observar a sinergia que eles produzem no desenvolvimento de ações ligadas ao esporte que promovam o desenvolvimento local.

A reflexão sobre as relações universidade-governo-indústria passa, necessariamente, pela avaliação da situação presente em diversos âmbitos da sociedade. No nosso caso, o foco recai sobre a sinergia desses atores no campo do esporte.

Um movimento abrangente, que busca favorecer o crescimento cíclico, espiral, cumulativo e contínuo do processo criativo e inovador é preconizado no modelo denominado hélice tríplice, em inglês triple helix (ETZKOWITZ; LEYDESDORFF, 1996).

De acordo com Silva, Terra e Votre (2006, p. 28) nesse modelo de análise sociológica,

A expectativa é que as universidades formem agentes multiplicadores das ações de inovação e mudança, que os governos contribuam com a criação, aperfeiçoamento e consolidação de políticas públicas, com mecanismos de fomento a essas ações, e que as empresas integrem, com base na responsabilidade social, os projetos de desenvolvimento; como parceiras dos dois outros atores.

Para Borges (2006), desde meados do século XX, especialistas das áreas de ciência e tecnologia têm reafirmado que o processo 
de desenvolvimento deveria ser resultado da ação múltipla e coordenada de três elementos fundamentais para o desenvolvimento das sociedades contemporâneas: o governo, a estrutura produtiva e a infraestrutura de ciência e tecnologia.

Autores como Etzkowitz e Leydesdorff (1996, 2000); Mello (2004); Silva, Terra e Votre (2006), Almeida (2008), entre outros, apontam a hélice tríplice como um novo modelo de compreensão da articulação entre as diversas esferas sociais.

$\mathrm{Na}$ perspectiva da hélice tríplice, a inovação e o desenvolvimento local ocorrem a partir de três espaços não-lineares: os espaços do conhecimento, do consenso e da inovação, que se sobrepõem e se multifertilizam tendo como cerne o papel transformador da universidade na sociedade.

Os projetos sociais esportivos têm se credenciado como uma das alternativas à prática das atividades físico-esportivas e também como veículo para a melhoria da autoestima e abertura de oportunidades no campo profissional.

Diante do exposto, busca-se verificar de que forma a interação entre universidade-governo-indústria está presente no Projeto Grael e que repercussões ela proporciona em termos de desenvolvimento local.

O estudo tem como objetivo geral promover a reflexão sobre o papel do esporte no desenvolvimento de regiões, focalizando diversos atores e mecanismos que possibilitam a organização de ações de incentivo ao desenvolvimento local.

Os objetivos específicos são: a) mapear as diferentes percepções que são elaboradas pelos atores do projeto face às expectativas geradas; b) analisar a sinergia entre universidade-governo-indústria nas ações do Projeto Grael e as repercussões na região onde o projeto está inserido.

Ações que incentivem e alavanquem a melhora da autoestima e da motivação em comunidades que apresentam vulnerabilidade social, permitem que o processo inclusivo ocorra efetivamente. A 
intenção deste trabalho é mostrar a interface que o esporte adquire na construção de ações de desenvolvimento e dar visibilidade ao Projeto Grael, participando da reflexão científica sobre a contribuição do esporte para o desenvolvimento local.

\section{A eVOluÇão do MOdELO HELICE TRÍPLICE}

De acordo com Etzkowitz e Leydesdorff (2000) o modelo hélice tríplice 1 pode ser analogicamente justaposto à perspectiva do triângulo de Sábato (1975). Neste caso, a esfera governamental abarca a universidade e a indústria, direcionando as relações que se constituem nessa rede. Esta formação foi muito utilizada por países socialistas do Leste Europeu e na antiga União Soviética; é considerada como uma configuração estática, mas nem por isso deixa de ter resultados.

O segundo modelo, a hélice tríplice 2, apresenta uma configuração laizzez faire entre a universidade, a indústria e o governo. As instituições apresentam-se com bordas bem definidas e sem interações fortes. Neste caso, as pás da hélice atuam de forma isolada e também produzem um movimento que se adapta bem a países onde há pouca interferência estatal nas relações interinstitucionais.

No terceiro modelo, a hélice tríplice 3, a interação entre as três pás se realiza de forma intensa. As relações que se constroem permitem que as instituições possam também exercer o papel da outra, produzindo organizações híbridas que surgem nas interfaces.

As diferentes pressões sociais levaram os teóricos da hélice tríplice a pensarem numa perspectiva substantiva além da já tradicional perspectiva instrumental. Assim, os valores têm se igualado às questões econômicas. Desta forma, Etzkowitz e Zhou (2006) desenvolveram um modelo denominado como hélices tríplices gêmeas (triple helix twins). Nesta perspectiva, a inovação implica não apenas o desenvolvimento econômico e social, mas também o meio ambiente, o planeta, a vida. Uma dimensão crítica é então introduzida no modelo tradicional. 


\section{Metodologia}

Optou-se pela abordagem de natureza qualitativa. Porém, não se descartou a quantificação de alguns dados. Neste sentido, Minayo (1994) afirma que os conjuntos de dados quantitativos e qualitativos não se opõem. Ao contrário, se intersectam, pois a realidade abrangida por eles interage dinamicamente, excluindo qualquer dicotomia.

Foi utilizada a observação participante, pois esta coloca o pesquisador em um contexto de apropriação dos signos e significados existentes nas relações cotidianas da estrutura, bem como seu relacionamento com os demais setores da sociedade.

Como o estudo de caso demanda a utilização de recursos variados, para possibilitar o maior universo possível de informações e, com isso, captar as diferentes singularidades, e investigar opiniões construídas coletivamente, o grupo focal constituiu-se num dos instrumentos para coletar os relatos dos agentes envolvidos. Do ponto de vista dos participantes, a dinâmica do grupo focal deve parecer "flexível e não estruturada, dando margem à discussão sobre qualquer assunto" (DIAS, 2000, p. 145). Além dessas estratégias, aplicou-se um questionário, respondido por um dos responsáveis pelo Projeto Grael.

A amostra para o grupo focal foi selecionada entre a equipe técnica, alunos e instrutores do projeto. Os convites foram encaminhados à secretaria do Projeto Grael, que solicitou voluntários para participar da pesquisa.

O processo de diálogo foi gravado, com o consentimento dos participantes, em fitas cassete, perfazendo um total de 6 horas de gravação. Este estudo foi aprovado pelo Comitê de Ética em Pesquisa da Universidade Salgado de Oliveira, sob o número 197/2008.

\section{ResultadOS E discussão}

O Projeto Grael é desenvolvido por uma organização não go- 
vernamental: o Instituto Rumo Náutico. Lars Grael, Torben Grael e Marcelo Ferreira, com o apoio da prefeitura de Niterói e a parceria dos professores de educação física Cintia Knoth e Luiz Evangelista, idealizaram o projeto em 1996.

Está localizado na praia de Jurujuba em Niterói/RJ, destinado a crianças da rede pública de ensino. O Instituto possui como missão: educar e disseminar o conhecimento náutico a partir da vela e de outras atividades marinheiras. Atende anualmente cerca de 900 pessoas ao ano, com idades entre 9 e 25 anos.

Segundo Davies (2006), o Projeto Grael baseou-se no princípio de que a vela garante caminhos de socialização a partir da educação e formação profíssional. A idéia começou a se materializar em junho de 1998, com o apoio da Empresa Niteroiense de Esporte, Lazer e Turismo - NELTUR, quando foram adquiridos os primeiros equipamentos e formada a equipe de instrutores.

Em setembro de 1999, o Projeto Grael expandiu sua área de atuação, implantando um núcleo na cidade de Vitória/ES, apoiado pela Prefeitura Municipal de Vitória e pelo Iate Clube do Espírito Santo. Os dois núcleos se estruturaram com a participação decisiva das administrações municipais, suprindo os recursos financeiros necessários para a contratação de pessoal e aquisição de equipamentos.

Voltado a estudantes pobres da rede pública municipal de ensino, o Projeto Grael apresenta-se com ênfase explícita na profissionalização (DAVIES, 2006). Embora a profissionalização como atleta de uma das categorias do iatismo seja considerada possível para os mais talentosos, o Projeto Grael divide-se em vários programas que visam, principalmente, a produção de profissionais ligados às diversas atividades do mundo da vela. Há iniciação à mecânica, eletrônica e eletricidade, além de artesanato náutico, noções de ecologia, primeiros socorros e prevenção a incêndios. Os jovens são também preparados na área profissional esportiva para atuarem como árbitros de regata. Além de terem a possibilidade de obter habilitação profissional pela Marinha do Brasil. 
Embora o Projeto Grael esteja centrado em uma atividade marcada no campo esportivo pelo signo da distinção (BOURDIEU, 1983, 1990). Ao se construir clara e explicitamente como proposta pedagógica profissionalizante nas artes náuticas, reencontra, sob esta perspectiva, uma antiga tradição da cultura operária do município de Niterói, que tem na indústria naval um de seus marcos mais importantes (GUEDES, 1997).

\subsection{QUESTIONÁRIO DE INDICADORES}

O quadro 1 apresenta os indicadores que foram levantados, por meio de um questionário, junto a um dos responsáveis pelo funcionamento do Projeto Grael. Na sequência, são apresentados os resultados obtidos por meio da entrevista com o grupo focal e os apurados com a observação participante.

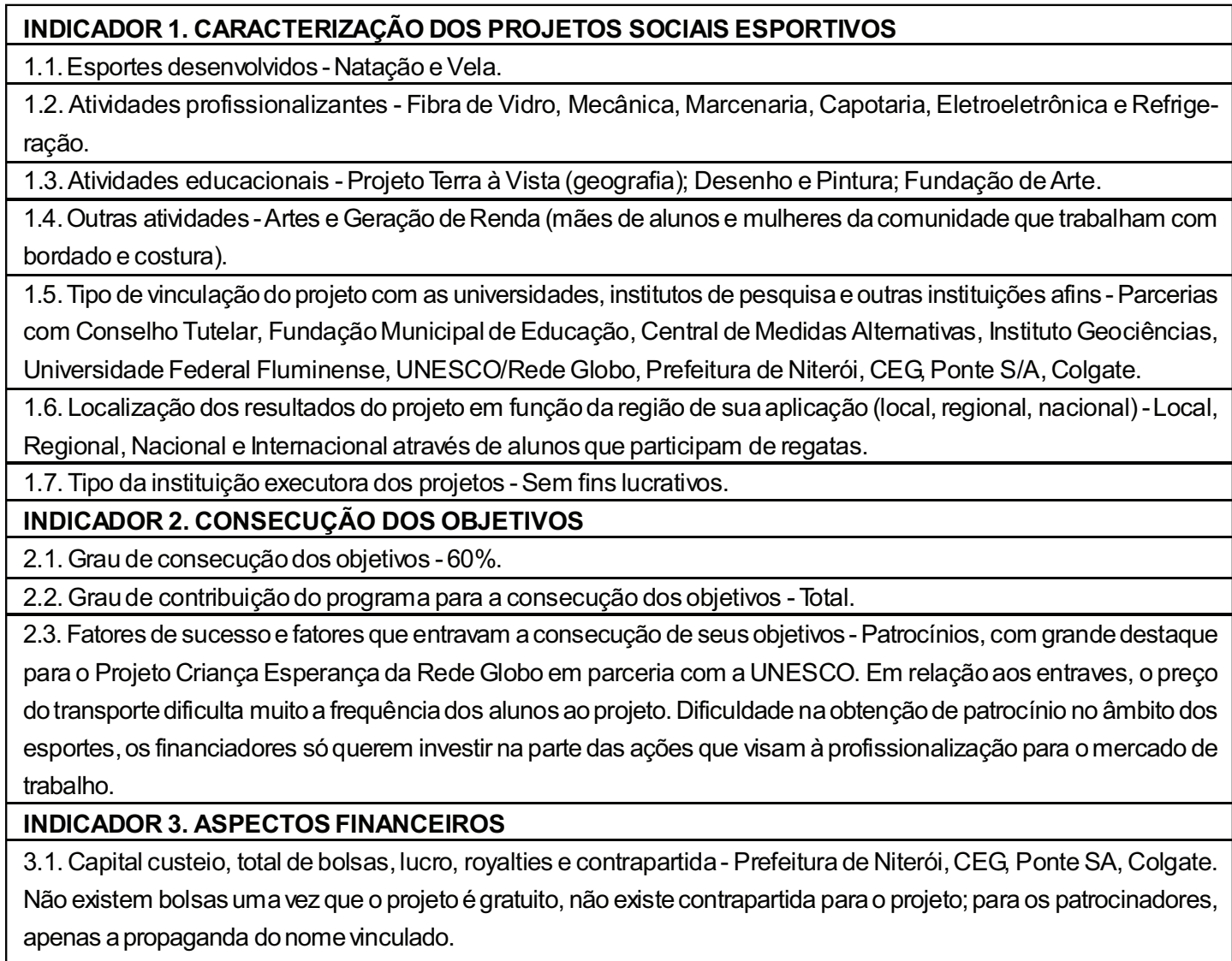

Wovimento, Porto Alegre, v. 16, n. 03, p. 221-239, julho/setembro de 2010. 


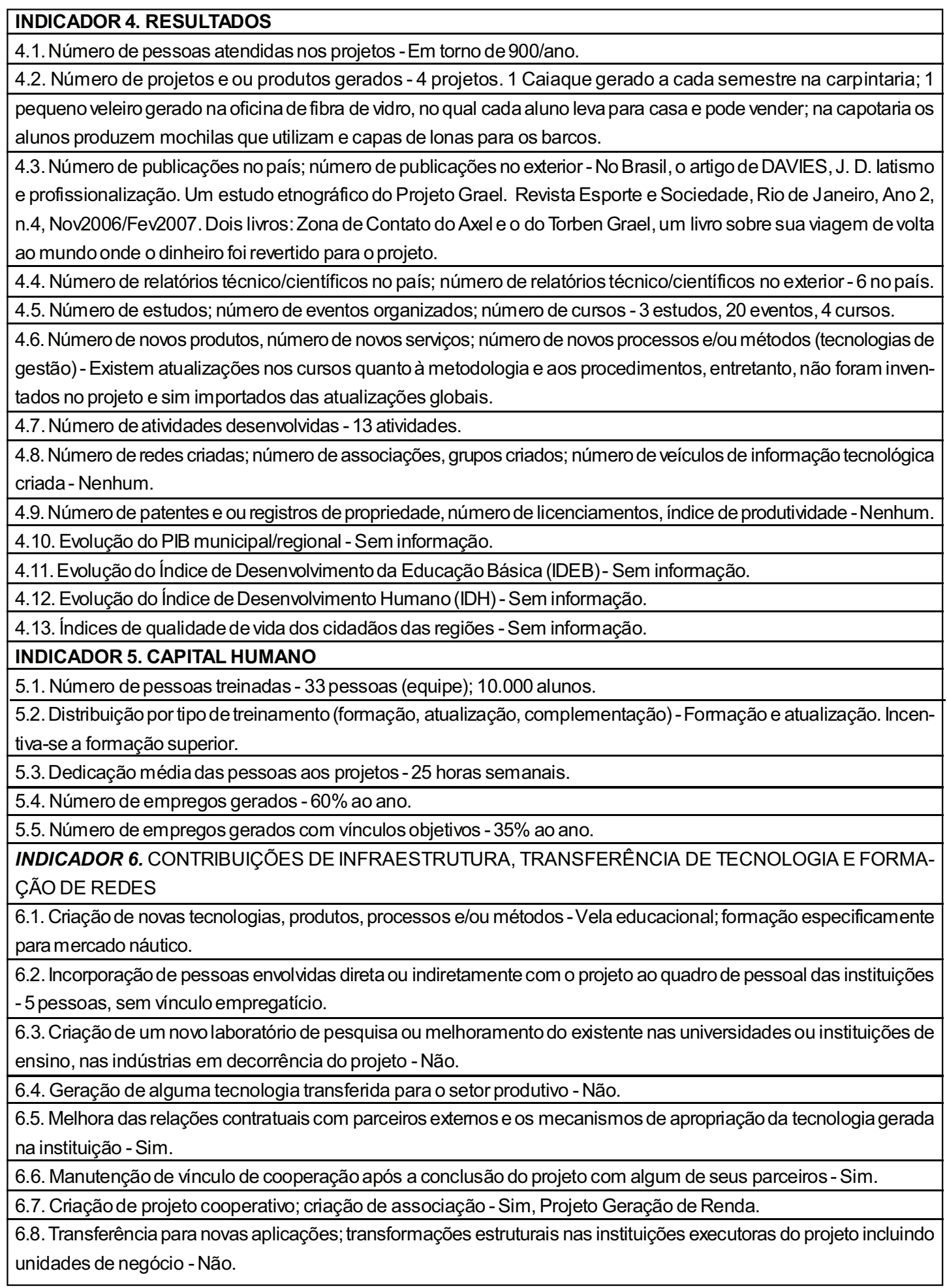

Quadro 1 - Questionário de Indicadores. Fonte: dos autores 


\subsection{ENTREVISTA COM GRUPO FOCAL}

A entrevista foi realizada com 14 pessoas que atuam no projeto, incluindo alunos, ex-alunos, instrutores e equipe técnica. Iniciouse o grupo focal com a seguinte pergunta: quais são os âmbitos de atuação do Projeto Grael?

Cara, no âmbito educacional, o projeto me ensinou muito. Através da vela aprendi a ter mais disciplina, mais respeito com os demais alunos e mais convívio social.

$\mathrm{Na}$ área profissional, o projeto me deu a oportunidade de fazer cursos de capacitação e me preparou com palestras, e muito estudo teórico, e prático, para ser um profissional, e me lançar no mercado de trabalho.

Dois âmbitos foram destacados nas falas: educacional e profissional. No âmbito educacional foram ressaltados o ensino, a disciplina, o respeito e o convívio social; no âmbito profissional, a capacitação profissional e a competência teórico-prática para atuar no mercado de trabalho.

Em seguida o grupo focalizou os âmbitos do esporte e do lazer.

Dá oportunidade de praticar um esporte considerado de elite, pois os equipamentos são muito caros e ainda mostrar que eles podem e devem se divertir sem precisar estar fazendo coisas erradas.

Pô!, me proporciona viajar para fora do estado e me faz competir campeonatos de nível nacional e internacional, e como a vela é um esporte que tem como cenário o mar, se torna muito divertido e dinâmico o contato com a natureza se misturando ao lúdico.

O grupo manifesta-se de maneira inclusiva ressaltando a experiência própria, estendendo-se aos atuais alunos. Os discursos apontam para a natureza lúdica das atividades e também para uma dimensão do esporte como meio de educação e de lazer para a preservação do meio ambiente. 
Prosseguiu-se destacando a seguinte sentença: de onde vem o conhecimento dos profissionais responsáveis por cada setor dentro do projeto, grau de instrução e qualificação dos profissionais?

A maioria dos professores tem o conhecimento adquirido pelo convívio, pois passaram por situação ou ouviram falar, muitos têm curso de formação, palestras e etc.

Mas alguns têm cursos técnicos, e outros são formados, e uns terceiros que estão começando a faculdade, dois aqui começaram por influência dos pais.

Verifica-se que existe um conhecimento tácito construído no projeto. Nestas falas, não se percebe a participação da universidade como a instituição que efetivamente faz a transferência do conhecimento para o empreendimento. Mantendo-se o mesmo foco, buscou-se compreender como a universidade atua em relação ao projeto.

E a universidade, como vocês enxergam a participação dela aqui dentro? Existe universidade aqui?

No momento não existe nenhuma parceria com alguma universidade, se houvesse seria um ótimo apoio.

Não cara tem a UFF.

É, a participação da UFF é apenas com o curso terra à vista de consciência ambiental.

Ela tem ajudado com algumas parcerias de cursos técnicos como metereologia, oceanografia e meio ambiente.

Eu penso que seria importante para capacitar melhor os professores e incentivar os alunos para no futuro entrarem em uma faculdade, dando bolsas, incentivando.

Seria bom se tivesse a participação de universidades com bolsas e formação dos professores do projeto. 
Observa-se que a expectativa sobre a participação da universidade prevalece em relação à sua atuação. Essas novas formas de participação revelam-se importantes diante da forma clássica de atuação da universidade; entretanto, cobra-se dela uma maior participação, visto que faz parte de um contexto que demanda sua atuação como protagonista na transformação da sociedade.

E as outras empresas, outras organizações, ONGs etc.? Todos ficaram em silêncio. $\mathrm{O}$ projeto precisa de uma comunicação com as demais empresas. Foi possível verificar que existe um desconhecimento em relação às parcerias, principalmente, financeiras. $\mathrm{O}$ debate prosseguiu com aspectos de cunho econômico e lançou-se a seguinte questão: falando em incentivo, em momento de crise, como os atores do projeto lidam com essas questões?

Com os nervos à flor da pele, quando o salário não sai, ficamos quatro meses sem receber porque o governo não estava pagando, era um olhar um para cara do outro aqui e quase nos matávamos de tanto mau humor.

Vínhamos dar aula por amor, precisou de muita conversa e paciência para controlar a situação. A diretoria correu atrás, nessa questão superamos isso.

Os depoimentos confirmam que ainda não é claro a participação de outras empresas que possam dar sustentabilidade ao projeto; a prefeitura é a única responsável pelo pagamento dos salários. A busca por parcerias com empresas, pela via da responsabilidade social, poderia trazer o equilíbrio econômico necessário ao bom andamento das ações.

Foi então introduzida a seguinte questão: como vocês avaliam a participação do governo (prefeitura) em relação ao projeto?

Todos disseram: "paga o meu salário", porém um dos presentes acentuou que eles falham muito. Como assim falham? Como vocês percebem as expectativas dos mesmos em relação ao projeto?

O que eu sinto é que eles não ligam muito, enquanto der para manter e apoiar eles farão, assim que tiver que cortar gastos seremos os primeiros. 
Penso que eles esperam que o projeto auxilie os alunos da rede municipal de ensino, e ajudar com a retirada das crianças das ruas, e ajudar na integração social.

Percebe-se a existência de um desapontamento em relação à atuação da prefeitura, apesar de ser a principal financiadora do projeto.

Como se dá a interlocução com as famílias?

Reunião com os pais no início e no término do curso e conversamos com a família apenas dos problemáticos.

Eles vêm perguntando como estão indo; falam de algumas preocupações deles e pedem que os ajudem a instruir, e fazemos de maneira sutil ou até chamamos para conversar em particular, ainda contamos com a ajuda da psicóloga que conversa com os pais dos alunos também.

Temos psicóloga aqui também que ajuda a lidar com os problemas dos alunos.

Neste trecho, nota-se que o trabalho de acompanhamento não se restringe apenas aos instrutores. O profissional de psicologia atua num nível de atendimento primário integral, disposto a contribuir com a proteção e recuperação do aluno e sua família, encaminhando, conforme a necessidade, a participação de diferentes profissionais e garantindo a continuidade do atendimento graças ao seu permanente vínculo com a família.

O que vocês apontariam como um elemento que dificulta a participação efetiva do aluno no projeto?

O projeto tenta buscar informações do por que eles pararam de participar, tenta se informar dos motivos deles e, quando eles voltam, é conversado para que não volte acontecer e em alguns casos ajudam a resolver o problema deles. 
Um grande agravante da evasão é o transporte, entretanto o projeto recebe os alunos de volta, de braços abertos, mas querendo saber o motivo e perguntando se vai acontecer de novo.

Verifica-se que o transporte é um dos principais fatores que dificulta a permanência dos alunos nas atividades. A falta de uma condução direta e os poucos recursos financeiros influenciam diretamente na evasão. Em alguns casos, os alunos têm de tomar duas conduções para chegar ao projeto.

Como o projeto lida com a questão dos ex-alunos? Existe alguma forma de controle para verificar se os mesmos estão inseridos no mercado de trabalho?

Depois que o aluno se forma encaminhamos eles para algum lugar, depois disso, se ele sai deste lugar, perdemos o contato, muitas vezes eles mudam o telefone e aí fica difícil localizar.

Existe um cadastro de monitoramento de alunos para trabalhar nesse mercado de trabalho.

O projeto tenta saber se estão empregados, se estão estudando e muitos saem do projeto empregados em clubes, marinas e em muitas vezes empresas de outros ramos como atendente, vendedor e etc.

Alguns são esquecidos, se alterar os dados da ficha de inscrição não tem mais contato.

Acho que ligando para saber como eles estão nos trabalhos indicados pelo projeto fica fácil de encontrar.

Conforme Putnam (1996), as associações engendram hábitos e espírito de cooperação e solidariedade na sociedade. O Instituto poderia estimular a criação de uma Associação de Egressos do Projeto Grael e um Portal do Egresso. 


\subsection{AOBSERVAÇÃO PARTICIPANTE}

Com o intuito de refletir sobre a dinâmica do projeto, utilizou-se como referência as características da cultura organizacional e as impressões dos diversos atores da equipe que foram captadas durante o período em que os pesquisadores estiveram em contato direto com o cotidiano do Projeto Grael.

Estas reflexões têm por objetivo pontuar os itens observados que possam auxiliar na identificação das forças e fraquezas do projeto. Na organização dos dados coletados nas observações, utilizamos a matriz SWOT, que de acordo com Bechara (2008) significa: strenghts - pontos fortes; weakness - pontos fracos; opportunities oportunidades e threats - ameaças. Os itens classificados como pontos fortes e pontos fracos compõem o ambiente interno; os itens oportunidades e ameaças, o ambiente externo.

A presença de Torbem, Lars, Axel, como padrinhos do projeto.

Gratuidade.

Destinado a jovens da rede pública de ensino.

Apoio da Prefeitura.

O ensino à vela e os cursos profissionalizantes inseridos em sua proposta.

Alunos qualificados e indicados para o mercado de trabalho.

Parcerias com órgãos importantes: Ministério do Esporte e vários conselhos, como o Conanda.

Melhoria das perspectivas de vida dos alunos e das famílias, possibilidade de novos horizontes.

O comprometimento dos funcionários do projeto.

Quadro 2 - Pontos fortes

Necessidade de uma maior divulgação, muitos pais temem que o projeto não seja gratuito por falta de informação.

Dificuldade de translado para o projeto, o lugar é distante, normalmente duas passagens para ir e para voltar, no total: quatro passagens.

Necessidade de uma ação mais efetiva das universidades dentro do projeto, pesquisando, capacitando e incentivando

Pouco conhecimento em relação à pesquisa pelo próprio projeto.

Quadro 3 - Pontos fracos

Pouca participação das indústrias e da prefeitura acompanhando as ações do projeto. Perda das parcerias.

Dependência da verba da Prefeitura.

Quadro 4 - Ameaças

ovimento, Porto Alegre, v. 16, n. 03, p. 221-239, julho/setembro de 2010. 
Responsabilidade Social das Empresas - Com a intensificação dos projetos de responsabilidade social há um espaço nas empresas para ações que promovam a superação das desigualdades sociais, a partir de parcerias e redes de inovação. Bolsas e Incentivos - Há espaço para a busca por convênios com universidades do entorno, de modo a permitir o acesso e a permanência de egressos do projeto no ensino superior. A contrapartida poderia ser a participação dos atletas em equipes da universidade, a vinculação da universidade com o Projeto Grael, a realização de cursos de extensão com a supervisão do Projeto Grael.

Incubadoras - Aproximar-se de universidades com incubadoras. Viabilizar a criação de pequenas empresas por parte de egressos pode ser uma alternativa para a geração de renda e transformação social dessas famílias.

Quadro 5 - Oportunidades

\section{CONCLUSÃo}

Este estudo buscou analisar a sinergia produzida entre universidade-indústria-governo no Projeto Grael. O argumento hélice tríplice foi utilizado como referencial teórico-metodológico para compreender o impacto das ações do Projeto Grael na cidade de Niterói.

Os dados coletados apontam que o Projeto Grael tem na prefeitura de Niterói sua grande âncora. Apesar de existirem indústrias patrocinadoras, o governo, no caso a prefeitura, tem se mostrado como o parceiro mais forte; foi essa instituição que estimulou a criação do Projeto Nomes, do qual faz parte o Projeto Grael, e é efetivamente quem paga os salários dos funcionários.

A ação das indústrias se dá basicamente por meio de patrocínios, havendo necessidade de uma presença efetiva, acompanhando as ações desenvolvidas. Verifica-se também a necessidade de uma participação pró-ativa quanto às possibilidades de abertura de oportunidades no mercado de trabalho para os jovens egressos. Em relação ao aspecto financeiro, a participação das indústrias é importante; entretanto, sem o apoio da prefeitura, o projeto não se sustentaria.

A universidade participa de forma tímida. De acordo com os relatos, apenas a Universidade Federal Fluminense mantém uma interação na esfera do ensino. A geração da maior parte do conhecimento provém do Instituto Náutico e do saber tácito trazido pelos colaboradores. As universidades da região não têm se aproximado 
do Projeto, principalmente, nas áreas de pesquisa e extensão. Os relatos destacaram o quanto seria importante uma presença mais substantiva da universidade.

O esporte ocupa em nossa sociedade um lugar de destaque, logo se entende a importância da prática esportiva como instrumento de socialização, promoção da cidadania, sucesso profissional e pessoal. A utilização de estratégias de inclusão tem sido o foco de algumas instituições para combater as injustiças sociais e a falta de oportunidades geradas pelo sistema vigente. Entretanto, os relatos evidenciaram certo preconceito das empresas em patrocinar eventos ligados ao esporte, dando preferência àqueles vinculados a atividades de formação profissional e educacional.

Foi possível notar que as atividades esportivas existentes no Grael conjugam-se com o anseio dos pais/responsáveis e contribui no processo de inclusão social das crianças e dos adolescentes. Há necessidade, no entanto, de investimentos na infraestrutura.

Diretoria e funcionários da instituição têm conhecimento do impacto dessas atividades na melhoria da qualidade de vida, educação e socialização do seu público-alvo, no entanto, o fortalecimento do diálogo com demais setores da sociedade ampliaria as possibilidades para os egressos. A busca de apoio e patrocínio poderia ser feita por intermédio da criação de fóruns onde um espaço de consenso fosse desenvolvido pelo Instituto Náutico, universidades, indústrias, governo e comunidade, de forma a construir parcerias que pudessem impulsionar e ampliar o Projeto Grael.

Na perspectiva do modelo da hélice tríplice, as universidades, governos e indústrias devem repensar a forma de atuação e criar um canal de diálogo mais eficaz com os demais segmentos da sociedade. Os outros setores precisam compreender a universidade não apenas na instância acadêmica. Cabe a ela promover uma interrelação mais abrangente e coadunada com as necessidades da sociedade do conhecimento. 
The Nautical Sport and the Dynamics of Triple Helix in the Grael Project: a Case Study

Abstract: Some projects developed within the sport have been known for presenting innovative models. This study focuses on the Grael Project and its relations with government, industry and the university. It aims at promoting reflection on the role of sport in developing regions. The theoretical model of the triple helix is used to analyze the participation of different actors. The conclusion shows that the main project partner is the mayor of the city of Niteroi. The performance of industries, basically, is located in the sponsorship. The University participates in a shy way.

Keywords: Physical education. Social investiment projects. Sport.

El Deporte Náutico y la Dinámica de la Triple Hé-
lice En EI Proyecto Grael: un Estudio de Caso
Resumen: Algunos proyectos desarrollados en el
deporte han sido conocidos por la presentación de
modelos innovadores. Este estudio se centra en el
Proyecto Grael y sus relaciones con el gobierno, la
industria y la universidad. Su objetivo es promover la
reflexión sobre el papel del deporte en las regiones en
desarrollo. El modelo teórico de la triple hélice se utili-
za para analizar la participación de diferentes actores.
La conclusión muestra que el socio principal del
proyecto es el alcalde de la ciudad de Niterói. El
rendimiento de las industrias, básicamente, se
encuentra en el patrocinio. La Universidad participa
de una manera tímida.
Palabras clave: Educación física. Proyectos de
inversión social. Deportes.

\section{REFERÊNCIAS}

ALMEIDA, Mariza. Innovation and entrepreneurship in Brazilian universities. International Journal of Technology Management and Sustainable Development, United Kingdom, v. 1, n. 1, p. 38-59, 2008.

BECHARA, Marco. Modelo M4 para gestão de legados de megaeventos esportivos com foco na responsabilidade social e políticas públicas. In: DaCosta, Lamartine Pereira et al. Legados de megaeventos esportivos. Brasília: Ministério do Esporte, 2008.

Wovimento, Porto Alegre, v. 16, n. 03, p. 221-239, julho/setembro de 2010. 
BORGES, Maria Alice Guimarães. A tríplice hélice e o desenvolvimento do setor de tecnologia da informação do Distrito Federal. 2006. 317 f. Tese (Doutorado em Ciência da Informação) - Dep. de Ciência da Informação e Documentação, UNB, Brasília, 2006.

BOURDIEU, Pierre. Como é possível ser esportivo? In: BOURDIEU, Pierre. Questões de sociologia. Rio de Janeiro: Marco Zero, 1983.

Programa para uma sociologia do esporte. In: BOURDIEU, Pierre. Coisas ditas. São Paulo: Brasiliense, 1990.

DAVIES, Julio D'Angelo. Iatismo e profissionalização: um estudo etnográfico do Projeto Grael. Esporte e Sociedade, Rio de Janeiro, v. 2, n. 4, nov. 2006. Disponível em: <http://www.uff.br/esportesociedade/pdf/es407.pdf>. Acesso em: 7 ago. 2009.

DIAS, Claudia Augusto. Grupo focal: técnica de coleta de dados em pesquisas qualitativas. Informação \& Sociedade: Estudos, João Pessoa, v. 10, n. 2, p. 141158, 2000.

ETZKOWITZ, Henry; LEYDESDORFF, Loet. The dynamics of innovation: from National Systems and "Mode 2" to a Triple Helix of university-industry-government relations. Research Policy, Stanford, CA, USA, n. 29, p.109-123, 2000.

Universities in the global knowledge economy: a triple helix of academic-industry-government relations. Londres: Cassell, 1996

ETZKOWITZ, Henry; ZHOU, Chunyan. Triple Helix twins: innovation and sustainability. Science and Public Policy, United Kingdom, v. 33, n. 1, p. 77-83, 2006.

GUEDES, Simoni Lahud. Jogo de corpo: um estudo de construção social de trabalhadores. Niterói: Eduff, 1997.

MELLO, José Manoel Carvalho. A abordagem hélice tríplice e o desenvolvimento regional. In: SEMINÁRIO INTERNACIONAL EMPREENDEDORISMO, PEQUENAS E MÉDIAS EMPRESAS E DESENVOLVIMENTO, 2., Rio de Janeiro, 2004. Disponível em: < http://www.itoi.ufrj.br/seminario/anais/Tema\%201-2-MELLO.pdf>. Acesso em: 06 jun. 2009.

MINAYO, Maria Cecília de Souza (Org.) Pesquisa social: teoria, método e criatividade. Petrópolis: Vozes, 1994.

PUTNAM, Robert. Comunidade e democracia: a experiência da Itália moderna. Rio de Janeiro: FGV, 1996.

SÁBATO, Jorge. El pensamiento latinoamericano en la problemática cienciatechnología-desarrollo-dependencia. Buenos Aires: Paidós, 1975. 
SILVA, Carlos Alberto Figueiredo da; TERRA, Branca. VOTRE, Sebastião Josué. O modelo da hélice tríplice e o papel da educação física, do esporte e do lazer no desenvolvimento local. Revista Brasileira de Ciências do Esporte, Campinas, v. 28 , p. $167-183,2006$. 